\title{
Comparison of Rectangular and Elliptical Control Region EWMA Schemes for Joint Quality Monitoring
}

\author{
A. M. Razmy ${ }^{1}$, T. S. G. Peiris ${ }^{2}$ \\ ${ }^{1}$ Department of Mathematical Sciences, Faculty of Applied Sciences, South Eastern University of Sri Lanka, \\ Sammanthurai, Sri Lanka \\ ${ }^{2}$ Department of Mathematical Sciences, Faculty of Engineering, University of Moratuwa, Moratuwa, Sri Lanka \\ Email: amrazmy@seu.ac.lk
}

Received 4 October 2014; revised 2 November 2014; accepted 18 November 2014

Copyright (C) 2014 by authors and Scientific Research Publishing Inc.

This work is licensed under the Creative Commons Attribution International License (CC BY). http://creativecommons.org/licenses/by/4.0/

c) (i) Open Access

\begin{abstract}
The exponential weighted moving average technique used in process mean and variance monitoring charts was combined by Gan in 1997 and proposed two combined joint monitoring schemes one with rectangular control region and the other with elliptical control region. Performance of these two schemes may very depend on the shifts in mean or variance to be detected quickly. In this paper, performances of these two schemes are evaluated with respect to the average run length properties. The results reveal that elliptical scheme is little faster in detecting the shifts in process mean and increase in variance within a limit.
\end{abstract}

\section{Keywords}

Average Run Length, Exponential Weighted Moving Average, Joint Monitoring

\section{Introduction}

Exponential weighted moving average (EWMA) chart for monitoring a shift in process mean was introduced by Roberts in 1959 and the design procedure of EWMA mean charts was reported by Crowder in 1989 [1] [2]. Later Chang and Gan showed that EWMA chart can also be used to monitor the sample variance [3]. However, Gan emphasized the importance of jointly monitoring the mean and variance, as that process monitoring is a bivariate problem [4] [5]. The current practice of joint monitoring scheme consists of a mean and a variance chart to look a bivariate problem using two univariate procedures. Two combined joint monitoring schemes using EWMA charts with a rectangular control region $\left(\mathrm{EE}_{\mathrm{r}}\right)$ and an elliptical control region (EE $\mathrm{E}_{\mathrm{e}}$ ) were proposed by Gan [4]. 
When there is more than one scheme for joint monitoring, it is needed to compare the performances of the schemes under different scenarios. The performance of individual EWMA chart was studied using its run length distribution by Crowder, Lucas and Saccucci [6] [7]. In this paper the performance of the $\mathrm{EE}_{\mathrm{r}}$ and $\mathrm{EE}_{\mathrm{e}}$ schemes is evaluated different scenarios based on average run length (ARL) properties. ARL is defined as the average number of samples taken until an out-of-control signal is issued in quality control schemes.

\section{Methodology}

An EWMA chart for monitoring the sample mean $\bar{X}_{t}$ is obtained by plotting $E_{t}=\left(1-\lambda_{E}\right) E_{t-1}+\lambda_{E} \bar{X}_{t}$ against the sample number $t(t=1,2, \cdots)$, where $E_{0}$ is usually set at target mean $\mu_{0}, \lambda_{E}$ is a constant such that $0<\lambda_{E}<1$ and it is selected based on the shift in the mean to be detected quickly. An out-of-control signal is issued if $H_{E}<E_{t}<h_{e}$, where $H_{E}$ and $h_{E}$ are the upper control limit and lower control limit respectively. The EWMA chart for monitoring the sample variance $S_{t}^{2}$ can be obtained by plotting $e_{t}=\left(1-\lambda_{e}\right) e_{t-1}+\lambda_{e} \log \left(S_{t}^{2}\right)$ against the sample number $t$, where $e_{0}$ is usually set at $E\left[\log \left(S_{t}^{2}\right)\right], \lambda_{e}$ is a positive constant such that $0<\lambda_{e}<1$ and it is selected based on the shift in the variance to be detected quickly. An out-of-control signal is issued if $e_{t}$ is greater than the $H_{e}$ or $e_{t}$ is less than the $h_{e} . H_{e}$ and $h_{e}$ are the upper and lower control limits respectively for the EWMA variance chart.

In the $E_{\mathrm{r}}$ scheme, EWMA mean chart and the EWMA variance chart are combined by plotting the EWMA of $\log \left(S_{t}^{2}\right)$ against the EWMA of $\bar{X}_{t}$. The upper and lower control limits of the two charts form four sides of a rectangular control region. In $\mathrm{EE}_{\mathrm{e}}$ scheme, the distance from the point $E\left(\bar{X}_{t}\right), E\left(\log \left(S_{t}^{2}\right)\right)$ will decide whether a point falls inside the elliptical control region or not. This distance is calculated using Hotelling type statistics $T^{2}$ for each sample. The quantity $T_{t}^{2}$ for a point in which $e_{t}$ is greater than $E\left(\log \left(S_{t}^{2}\right)\right)$ is given as

$$
T_{t}^{2}=\frac{\left(E_{t}-\mu_{0}\right)^{2}}{H_{E}^{2}}+\frac{\left[e_{t}-E\left(\log \left(S_{t}^{2}\right)\right)\right]^{2}}{\left[H_{e}-E\left(\log \left(S_{t}^{2}\right)\right)\right]^{2}}
$$

and for a point in which $e_{t}$ is less than $E\left(\log \left(S_{t}^{2}\right)\right), T_{t}^{2}$ is given as

$$
T_{t}^{2}=\frac{\left(E_{t}-\mu_{0}\right)^{2}}{H_{E}^{2}}+\frac{\left[e_{t}-E\left(\log \left(S_{t}^{2}\right)\right)\right]^{2}}{\left[h_{e}-E\left(\log \left(S_{t}^{2}\right)\right)\right]^{2}} .
$$

Figure 1 illustrates the difference between the rectangular and elliptical control regions in which point $B$ is an in-control point with respect to the $\mathrm{EE}_{\mathrm{r}}$ scheme, but it is an out-of control point with respect to the $\mathrm{EE}_{\mathrm{e}}$ scheme. Similarly, point A is an out-of-control point with respect to the $E_{\mathrm{r}}$ scheme, but it is an in-control point with respect to the $\mathrm{EE}_{\mathrm{e}}$ scheme. In process monitoring, both the magnitude of the shift and the direction are important and therefore it advisable to plot the individual samples.

Simulated data set were used for comparing the performance of the two combined schemes. For this simulation, the in-control mean $\left(\mu_{0}\right)$ and variance $\left(\sigma_{0}\right)$ are assumed to be 0 and 1 respectively with sample size 5 . This means each sample comprises 5 normally distributed observations. The optimal parameters for constructing these schemes were obtained for two commonly used ARLs 250 and 370 and rechecked by simulation performed in SAS using proc RANNO. Simulations were run until the standard error of the ARL was less than 1\% of the pre-specified ARL. The control chart parameters of these two schemes for in-control ARL's of 250 and 370 are given in Table 1.

The performances of the schemes are compared based on out of control ARLs when there is a shift in mean or variance or in both. Schemes detect various magnitudes of shifts in mean and variance based on their sensitivities. The scheme which gives smaller ARL when there is a shift in mean or variance is the better scheme. The shifts in mean and variance investigated are given by

$$
\mu=\mu_{0}+\Delta \frac{\sigma_{0}}{\sqrt{n}}
$$

and

$$
\sigma=\delta \sigma_{0}
$$


Table 1. Control Chart parameters for the $\mathrm{EE}_{\mathrm{r}}$ and $\mathrm{EE}_{\mathrm{e}}$ schemes in a steady state when $\mathrm{ARL}=250$, 370 and $n=5$.

\begin{tabular}{cccc}
\hline Scheme & Control Region & Control Chart Parameters ARL $=250$ & Control Chart Parameters ARL $=370$ \\
& & $\lambda_{E}=0.134, E_{0}=0$ & $\lambda_{E}=0.120, E_{0}=0$ \\
& & $H_{E}=0.345, h_{E}=-0.345$ & $H_{E}=0.3385, h_{E}=-0.3385$ \\
$\mathrm{EE}_{\mathrm{r}}$ & Rectangular & $\lambda_{e}=0.106, e_{0}=-0.270$ & $\lambda_{e}=0.100, e_{0}=-0.270$ \\
& & $H_{e}=0.215, h_{e}=-0.867$ & \\
& & $H_{e}=0.2205, h_{e}=-0.8772$ \\
& & & \\
& & $\lambda_{E}=0.134, E_{0}=0$ & $\lambda_{E}=0.120, E_{0}=0$ \\
$\mathrm{EE}_{\mathrm{e}}$ & Elliptical & $H_{E}=0.372, h_{E}=-0.372$ & $H_{E}=0.3722, h_{E}=-0.3722$ \\
& & $\lambda_{e}=0.106, e_{0}=-0.270$ & $\lambda_{e}=0.100, e_{0}=-0.270$ \\
& $H_{e}=0.250, h_{e}=-0.92$ & $H_{e}=0.2540, h_{e}=-0.8994$ \\
& &
\end{tabular}

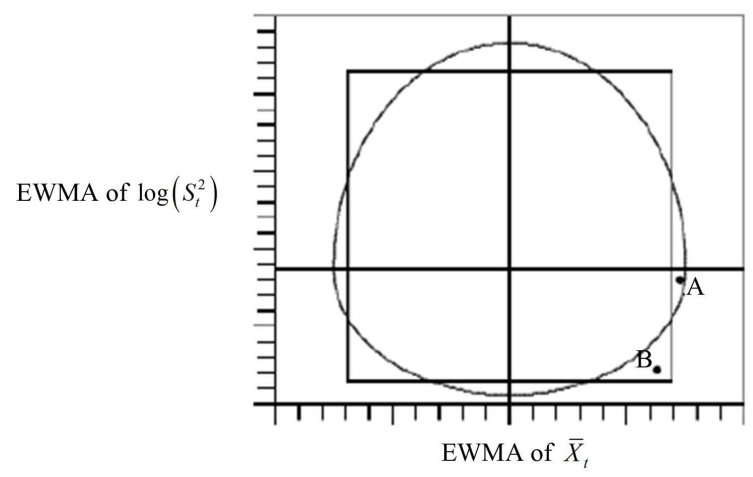

Figure 1. Rectangular and elliptical control regions of the combined EWMA schemes.

where $\Delta=0.0,0.2,0.4,0.6,1.0,1.5,3.0$ and $\delta=0.50,0.75,0.95,1.00,1.10,1.25,1.50,3.00$. The process is in-control when $\Delta=0.0$ and $\delta=1.00$ and otherwise the process has changed. For each scheme and each $(\Delta, \delta)$ combination 1,000,000 runs were performed to estimate the out-of-control ARL. The standard deviations of run length (SDRL) values were ensured that SDRL were less than $1 \%$ of the estimated ARL. For making the comparison, a comparison efficiency index $E_{(\Delta, \delta)}$ is introduced:

$$
E_{\Delta, \delta}=100-\frac{\left(\mathrm{ARL}_{\Delta, \delta}-\mathrm{ARL}_{\mathrm{Min}, \Delta, \delta}\right)}{\mathrm{ARL}_{\mathrm{Min}, \Delta, \delta}} \times 100
$$

where,

$E_{\Delta, \delta}=$ Comparative efficiency of a scheme for $\Delta$ shift in mean and $\delta$ shift in variance;

$\mathrm{ARL}_{\Delta, \delta}=\mathrm{ARL}$ for $\Delta$ shift in mean and $\delta$ shift in variance;

$\mathrm{ARL}_{\mathrm{Min}, \Delta, \delta}=$ Minimum ARL observed among $\mathrm{EE}_{\mathrm{r}}$ and $\mathrm{EE}_{\mathrm{e}}$ schemed for a $\Delta$ shift in mean and a $\delta$ shift in variance for particular in-control ARL.

\section{Results and Discussion}

Table 2 and Table 3 shows the out-of-control ARLs for different magnitudes of shifts in mean and variance for in-control ARLs of 250 and 370. Figure 2 and Figure 3 compare the efficiency of the two schemes using the index $E_{(\Delta, \delta)}$. According to the Table 2 and Table 3, in general, the $\mathrm{EE}_{\mathrm{r}}$ scheme performs very similar with $\mathrm{EE}_{\mathrm{e}}$ scheme. Figure 2 and Figure 3 shows when $\delta>1, \mathrm{EE}_{\mathrm{e}}$ scheme detect the shifts quicker than the $\mathrm{EE}_{\mathrm{r}} \mathrm{scheme}$ However this property is lost when $\Delta>1.5$ but it does not harm because after $\Delta>1.5$ both schemes detect the shifts very quickly. When $\delta<1, \mathrm{EE}_{\mathrm{e}}$ scheme gives larger out-of-control ARLs compare to the $\mathrm{EE}_{\mathrm{r}}$ scheme and therefore $E_{(\Delta, \delta)}$ index for $\mathrm{EE}_{\mathrm{e}}$ scheme is smaller compare to $\mathrm{EE}_{\mathrm{r}}$ scheme. This is a good property because decrease in variance is always favored. The design procedure of these schemes can be introduced through software for industrial use so that it can be a readymade scheme. 
Table 2. Average run lengths of combined schemes with respect to the process mean $\left(\mu=\mu_{0}+\Delta \frac{\sigma_{0}}{\sqrt{n}}\right)$ and standard deviation $\left(\sigma=\delta \sigma_{0}\right)$. In-control ARL $=250$.

\begin{tabular}{|c|c|c|c|c|c|c|c|}
\hline$\Delta$ & $\delta$ & $\mathrm{EE}_{\mathrm{r}}$ & $\mathrm{EE}_{\mathrm{e}}$ & $\Delta$ & $\delta$ & $\mathrm{EE}_{\mathrm{r}}$ & $\mathrm{EE}_{\mathrm{e}}$ \\
\hline 0 & 0.5 & 5.80 & 6.33 & 1 & 0.5 & 5.70 & 4.95 \\
\hline 0 & 0.75 & 21.90 & 24.57 & 1 & 0.75 & 9.66 & 8.58 \\
\hline 0 & 0.95 & 235.44 & 252.32 & 1 & 0.95 & 10.19 & 10.64 \\
\hline 0 & 1 & 250.00 & 250.00 & 1 & 1 & 10.14 & 10.55 \\
\hline 0 & 1.05 & 136.53 & 129.33 & 1 & 1.05 & 10.04 & 10.25 \\
\hline 0 & 1.1 & 67.70 & 63.44 & 1 & 1.1 & 9.86 & 9.78 \\
\hline 0 & 1.25 & 18.89 & 18.13 & 1 & 1.25 & 8.74 & 8.04 \\
\hline 0 & 1.5 & 8.17 & 7.9 & 1 & 1.5 & 6.40 & 5.83 \\
\hline 0 & 3 & 2.57 & 2.47 & 1 & 3 & 2.52 & 2.41 \\
\hline 0.2 & 0.5 & 5.79 & 6.27 & 1.5 & 0.5 & 4.89 & 4.05 \\
\hline 0.2 & 0.75 & 21.75 & 22.6 & 1.5 & 0.75 & 5.66 & 5.49 \\
\hline 0.2 & 0.95 & 134.57 & 135.1 & 1.5 & 0.95 & 5.74 & 6.03 \\
\hline 0.2 & 1 & 128.94 & 128.88 & 1.5 & 1 & 5.75 & 6.03 \\
\hline 0.2 & 1.05 & 88.34 & 83.03 & 1.5 & 1.05 & 5.76 & 5.97 \\
\hline 0.2 & 1.1 & 53.72 & 49.33 & 1.5 & 1.1 & 5.76 & 5.88 \\
\hline 0.2 & 1.25 & 18.02 & 16.96 & 1.5 & 1.25 & 5.66 & 5.46 \\
\hline 0.2 & 1.5 & 8.08 & 7.75 & 1.5 & 1.5 & 5.05 & 4.6 \\
\hline 0.2 & 3 & 2.57 & 2.46 & 1.5 & 3 & 2.46 & 2.34 \\
\hline 0.4 & 0.5 & 5.79 & 6.05 & 3 & 0.5 & 2.59 & 2.48 \\
\hline 0.4 & 0.75 & 20.46 & 18.43 & 3 & 0.75 & 2.60 & 2.71 \\
\hline 0.4 & 0.95 & 51.56 & 52.17 & 3 & 0.95 & 2.63 & 2.77 \\
\hline 0.4 & 1 & 48.54 & 49.24 & 3 & 1 & 2.64 & 2.77 \\
\hline 0.4 & 1.05 & 41.48 & 39.89 & 3 & 1.05 & 2.64 & 2.77 \\
\hline 0.4 & 1.1 & 32.82 & 30.27 & 3 & 1.1 & 2.65 & 2.77 \\
\hline 0.4 & 1.25 & 15.83 & 14.56 & 3 & 1.25 & 2.68 & 2.75 \\
\hline 0.4 & 1.5 & 7.83 & 7.42 & 3 & 1.5 & 2.71 & 2.68 \\
\hline 0.4 & 3 & 2.56 & 2.46 & 3 & 3 & 2.16 & 2.03 \\
\hline 0.6 & 0.5 & 5.79 & 5.74 & & & & \\
\hline 0.6 & 0.75 & 16.90 & 14.07 & & & & \\
\hline 0.6 & 0.95 & 24.43 & 25.13 & & & & \\
\hline 0.6 & 1 & 23.69 & 24.41 & & & & \\
\hline 0.6 & 1.05 & 22.20 & 21.92 & & & & \\
\hline 0.6 & 1.1 & 20.08 & 18.95 & & & & \\
\hline 0.6 & 1.25 & 13.17 & 11.98 & & & & \\
\hline 0.6 & 1.5 & 7.44 & 6.95 & & & & \\
\hline 0.6 & 3 & 2.55 & 2.44 & & & & \\
\hline
\end{tabular}


Table 3. Average run lengths of combined schemes with respect to the process mean $\left(\mu=\mu_{0}+\Delta \frac{\sigma_{0}}{\sqrt{n}}\right)$ and standard deviation $\left(\sigma=\delta \sigma_{0}\right)$. In-control ARL $=370$.

\begin{tabular}{|c|c|c|c|c|c|c|c|}
\hline$\Delta$ & $\delta$ & $\mathrm{EE}_{\mathrm{r}}$ & $\mathrm{EE}_{\mathrm{e}}$ & $\Delta$ & $\delta$ & $\mathrm{EE}_{\mathrm{r}}$ & $\mathrm{EE}_{\mathrm{e}}$ \\
\hline 0 & 0.5 & 6.23 & 6.45 & 1 & 0.5 & 6.16 & 5.18 \\
\hline 0 & 0.75 & 24.37 & 24.63 & 1 & 0.75 & 10.54 & 9.31 \\
\hline 0 & 0.95 & 331.51 & 310.88 & 1 & 0.95 & 11.09 & 11.81 \\
\hline 0 & 1 & 370.07 & 370.0 & 1 & 1 & 10.98 & 11.84 \\
\hline 0 & 1.05 & 186.01 & 185.27 & 1 & 1.05 & 10.88 & 11.53 \\
\hline 0 & 1.1 & 84.16 & 81.51 & 1 & 1.1 & 10.75 & 10.99 \\
\hline 0 & 1.25 & 21.22 & 20.56 & 1 & 1.25 & 9.62 & 8.94 \\
\hline 0 & 1.5 & 8.89 & 8.67 & 1 & 1.5 & 6.98 & 6.39 \\
\hline 0 & 3 & 2.76 & 2.67 & 1 & 3 & 2.72 & 2.6 \\
\hline 0.2 & 0.5 & 6.24 & 6.38 & 1.5 & 0.5 & 5.3 & 4.31 \\
\hline 0.2 & 0.75 & 24.35 & 22.98 & 1.5 & 0.75 & 6.12 & 6.01 \\
\hline 0.2 & 0.95 & 176.66 & 169.82 & 1.5 & 0.95 & 6.21 & 6.68 \\
\hline 0.2 & 1 & 166.54 & 175.29 & 1.5 & 1 & 6.23 & 6.7 \\
\hline 0.2 & 1.05 & 112.41 & 110.38 & 1.5 & 1.05 & 6.23 & 6.64 \\
\hline 0.2 & 1.1 & 65.66 & 61.8 & 1.5 & 1.1 & 6.23 & 6.56 \\
\hline 0.2 & 1.25 & 20.14 & 19.15 & 1.5 & 1.25 & 6.15 & 6.04 \\
\hline 0.2 & 1.5 & 8.83 & 8.53 & 1.5 & 1.5 & 5.5 & 5.04 \\
\hline 0.2 & 3 & 2.77 & 2.68 & 1.5 & 3 & 2.64 & 2.52 \\
\hline 0.4 & 0.5 & 6.27 & 6.2 & 3 & 0.5 & 2.85 & 2.75 \\
\hline 0.4 & 0.75 & 22.89 & 19.06 & 3 & 0.75 & 2.83 & 2.99 \\
\hline 0.4 & 0.95 & 59.98 & 62.22 & 3 & 0.95 & 2.84 & 3.05 \\
\hline 0.4 & 1 & 56.58 & 61.13 & 3 & 1 & 2.84 & 3.06 \\
\hline 0.4 & 1.05 & 47.87 & 48.81 & 3 & 1.05 & 2.85 & 3.05 \\
\hline 0.4 & 1.1 & 38.21 & 35.85 & 3 & 1.1 & 2.86 & 3.05 \\
\hline 0.4 & 1.25 & 17.7 & 16.33 & 3 & 1.25 & 2.88 & 3.01 \\
\hline 0.4 & 1.5 & 8.52 & 8.13 & 3 & 1.5 & 2.93 & 2.91 \\
\hline 0.4 & 3 & 2.77 & 2.66 & 3 & 3 & 2.34 & 2.2 \\
\hline 0.6 & 0.5 & 6.23 & 5.9 & & & & \\
\hline 0.6 & 0.75 & 18.84 & 14.94 & & & & \\
\hline 0.6 & 0.95 & 27.13 & 29.11 & & & & \\
\hline 0.6 & 1 & 26.29 & 28.42 & & & & \\
\hline 0.6 & 1.05 & 24.81 & 25.55 & & & & \\
\hline 0.6 & 1.1 & 22.6 & 21.85 & & & & \\
\hline 0.6 & 1.25 & 14.63 & 13.36 & & & & \\
\hline 0.6 & 1.5 & 8.12 & 7.57 & & & & \\
\hline 0.6 & 3 & 2.75 & 2.64 & & & & \\
\hline
\end{tabular}



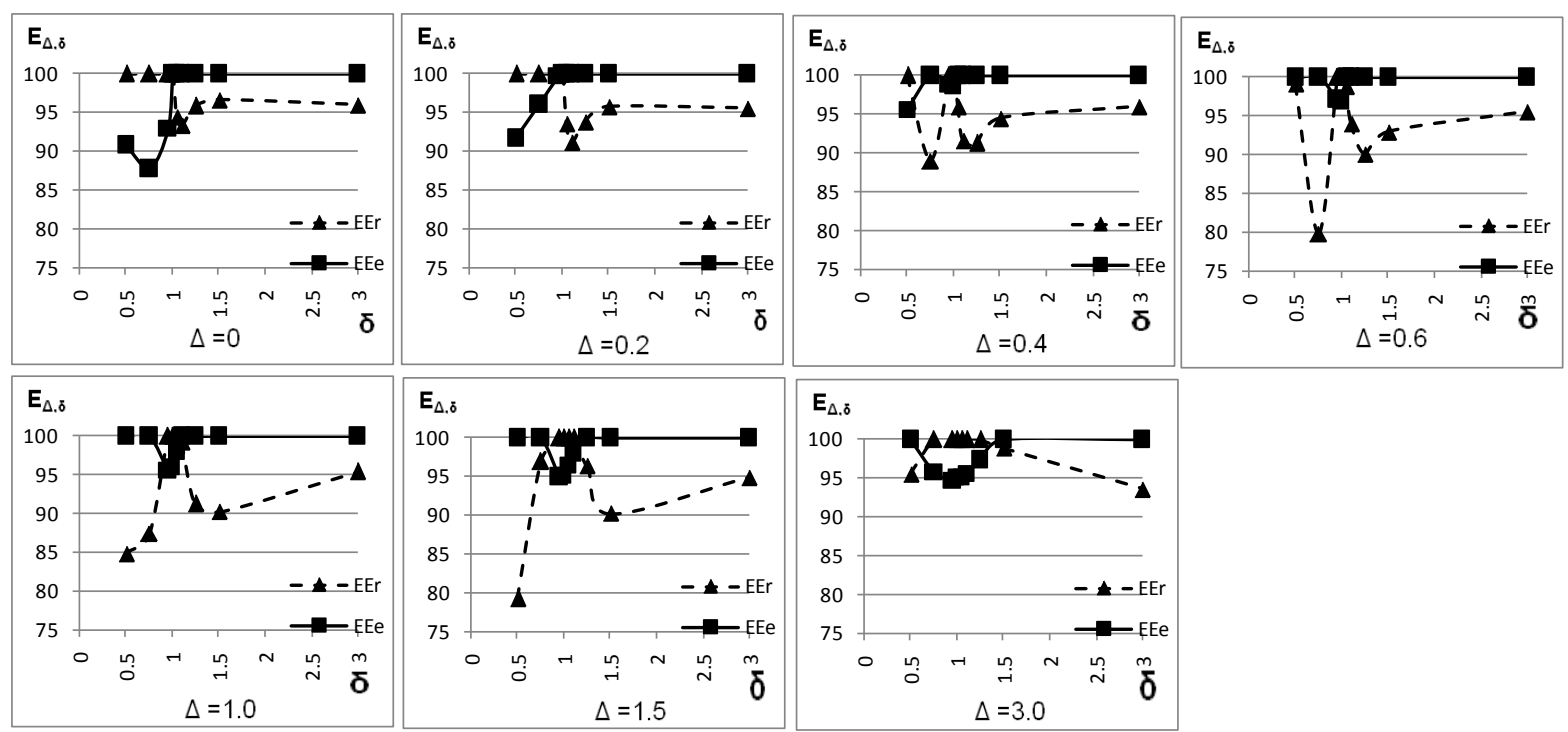

Figure 2. $E_{\Delta, \delta}$ index to compare the efficiency of $\mathrm{EE}_{\mathrm{r}}$ and $\mathrm{EE}_{\mathrm{e}}$ schemes when in-control $\mathrm{ARL}=250$.
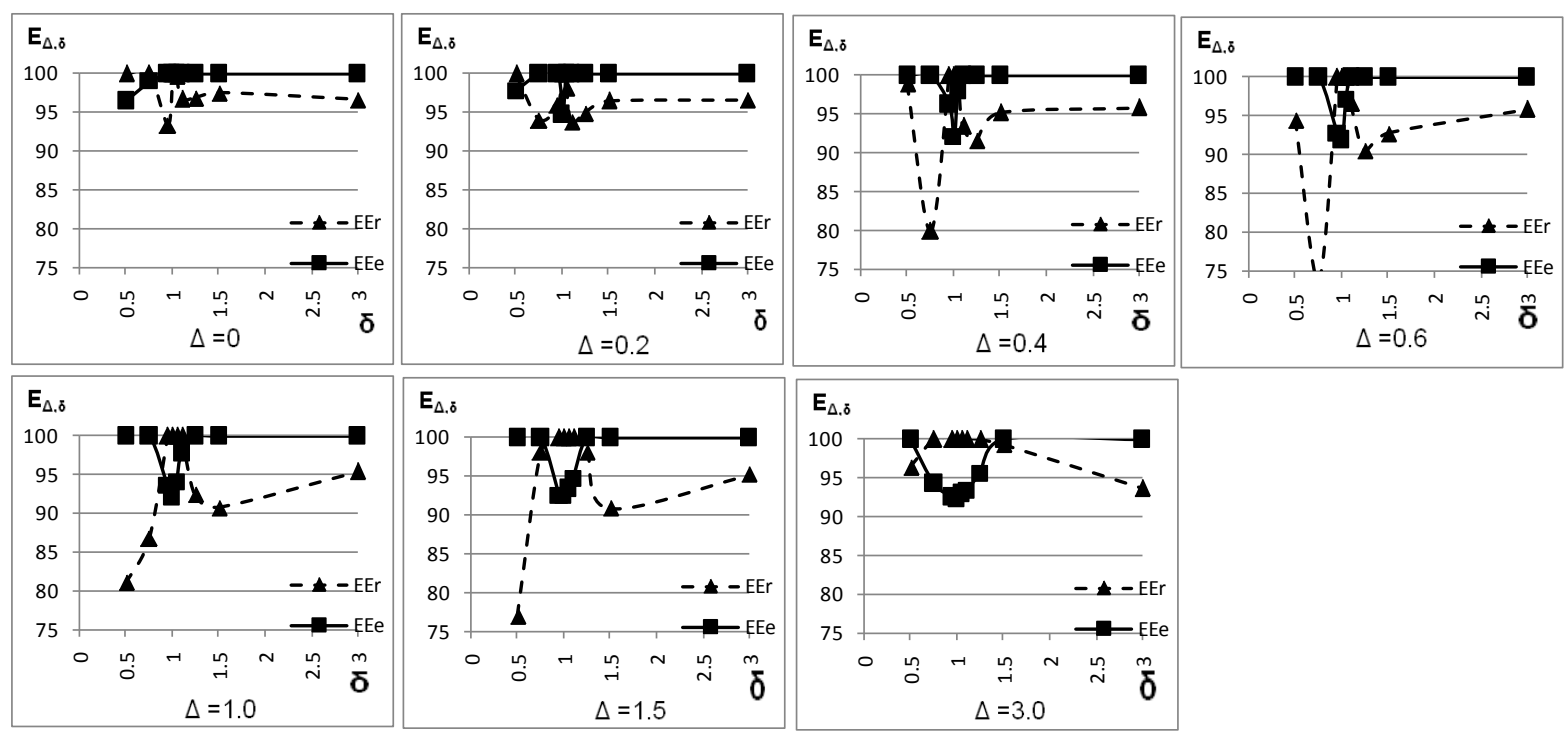

Figure 3. $E_{\Delta, \delta}$ index to compare the efficiency of $\mathrm{EE}_{\mathrm{r}}$ and $\mathrm{EE}_{\mathrm{e}}$ schemes when in-control $\mathrm{ARL}=370$.

\section{Conclusion}

In overall the $\mathrm{EE}_{\mathrm{e}}$ scheme is faster than the $\mathrm{EE}_{\mathrm{r}}$ scheme in detecting the shifts in process mean and variance but the design procedure of $\mathrm{EE}_{\mathrm{e}}$ scheme is little complex due to its complex equations. Further less variance is signaled slowly in the $\mathrm{EE}_{\mathrm{e}}$ schemes compare to $\mathrm{EE}_{\mathrm{r}}$ scheme which is a preferred characteristic. Therefore $\mathrm{EE}_{\mathrm{e}}$ scheme outperformed the $\mathrm{EE}_{\mathrm{r}}$ scheme.

\section{Acknowledgements}

This work was supported by the South Eastern University of Sri Lanka and the Higher Education for the Twenty First Century Project, Sri Lanka [SEUSL/O-AS/N1].

\section{References}

[1] Roberts, S.W. (1959) Control Chart Tests Based on Geometric Moving Averages. Technometrics, 1, 239-250. 
http://dx.doi.org/10.1080/00401706.1959.10489860

[2] Crowder, S.V. (1989) Design of Exponentially Weighted Moving Average Schemes. Journal of Quality Technology, 21, 155-162.

[3] Chang, T.C. and Gan, F.F. (1993) Optimal Designs of One-Sided EWMA Charts for Monitoring a Process Variance. Journal of Statistical Computing \& Simulations, 49, 33-48. http://dx.doi.org/10.1080/00949659408811559

[4] Gan, F.F. (1995) Joint Monitoring of Process Mean and Variance Using Exponentially Weighted Moving Average Control Charts. Technometrics, 37, 446-453. http://dx.doi.org/10.1080/00401706.1995.10484377

[5] Gan, F.F. (1997) Joint Monitoring of Process Mean and Variance. Nonlinear Analysis, Theory, Methods and Applications, 30, 4017-4024. http://dx.doi.org/10.1016/S0362-546X(97)00224-1

[6] Crowder, S.V. (1987) A Simple Method for Studying Run Length Distribution of Exponential Weighted Moving Average Charts. Technometrics, 29, 401-407.

[7] Lucas, J.M. and Saccuci, M.S. (1990) Exponentially Moving Average Control Schemes: Properties and Enhancements. Drexel University Faculty Working Series Paper, \#87-5. 
Scientific Research Publishing (SCIRP) is one of the largest Open Access journal publishers. It is currently publishing more than 200 open access, online, peer-reviewed journals covering a wide range of academic disciplines. SCIRP serves the worldwide academic communities and contributes to the progress and application of science with its publication.

Other selected journals from SCIRP are listed as below. Submit your manuscript to us via either submit@scirp.org or Online Submission Portal.
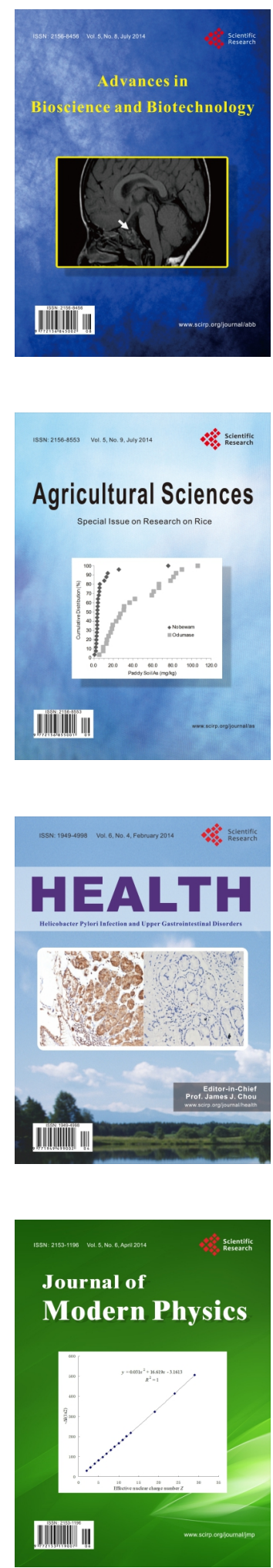
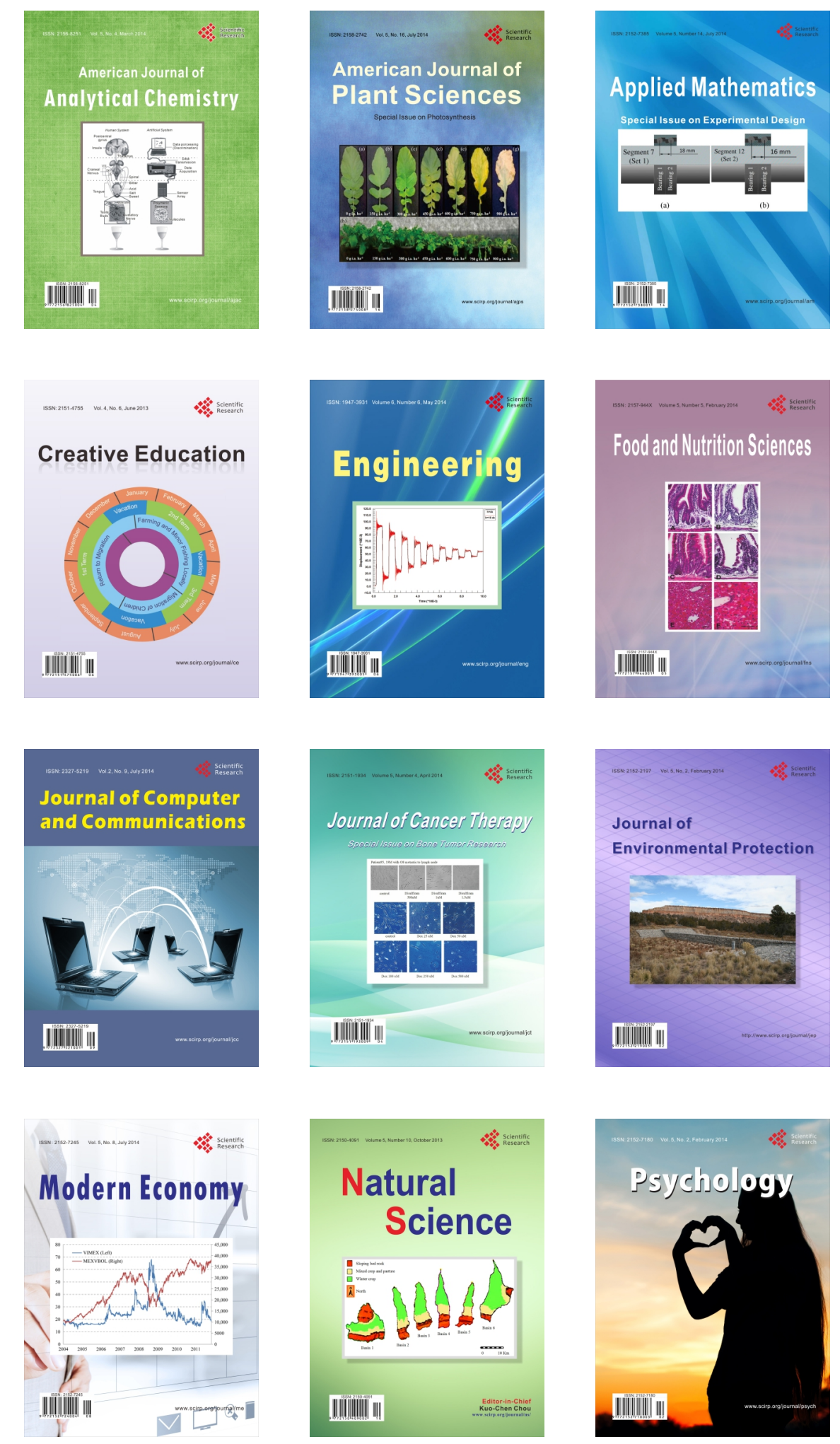